\title{
Lung Cancer Screening Practices of Primary Care Physicians: Results From a National Survey
}

Carrie N. Klabunde, $P b D^{1}$

Pamela M. Marcus, PbD

Paul K. J. Han, MD, MA, MPH

Thomas B. Richards, $M D^{3}$

Sally W. Vernon, $P b D^{4}$

Gigi Yuan, $M S^{5}$

Gerard A. Silvestri, $M D, M S^{6}$

'Applied Research Program, Division of Cancer Control and Population Sciences, National Cancer Institute, Bethesda, Maryland

${ }^{2}$ Center for Outcomes Research and Evaluation, Maine Medical Center, Portland, Maine

${ }^{3}$ Division of Cancer Prevention and Control, Centers for Disease Control and Prevention, Atlanta, Georgia

${ }^{4}$ Division of Health Promotion and Behavioral Sciences, University of Texas School of Public Health, Houston, Texas

${ }^{5}$ Information Management Services, Inc, Silver Spring, Maryland

${ }^{6}$ Division of Pulmonary and Critical Care Medicine, Medical University of South Carolina, Charleston, South Carolina

\begin{abstract}
PURPOSE Although current practice guidelines do not recommend screening asymptomatic patients for lung cancer, physicians may still order lung cancer screening tests. No recent national survey of health care professionals has focused on lung cancer screening. In this study, we examined the lung cancer screening practices of US primary care physicians and characteristics of those who order lung cancer screening tests.
\end{abstract}

METHODS We conducted a nationally representative survey of practicing primary care physicians in 2006-2007. Mailed questionnaires assessed the physicians' knowledge of lung cancer screening guidelines, beliefs about the effectiveness of screening tests, and ordering of screening chest radiograph, low-dose spiral computed tomography, or sputum cytology in the past 12 months. Clinical vignettes were used to assess the physicians' intentions to screen asymptomatic 50-year-old patients with varying smoking histories for lung cancer.

RESULTS A total of 962 family physicians, general practitioners, and general internists completed questionnaires (cooperation rate $=76.8 \%$ ). Overall, $38 \%$ had ordered no lung cancer screening tests; $55 \%$ had ordered chest radiograph, $22 \%$ low-dose spiral computed tomography, and less than 5\% sputum cytology. In multivariate modeling, physicians were more likely to have ordered lung cancer screening tests if they believed that expert groups recommend lung cancer screening or that screening tests are effective; if they would recommend screening for asymptomatic patients, including patients without substantial smoking exposure; and if their patients had asked them about screening.

CONCLUSIONS Primary care physicians in the United States frequently order lung cancer screening tests for asymptomatic patients, even though expert groups do not recommend it. Primary care physicians and patients need more information about lung cancer screening's evidence base, guidelines, potential harms, and costs to avert inappropriate ordering.

Ann Fam Med 2012;10:102-110. doi:10.1370/afm.1340.

\section{INTRODUCTION}

L

ung cancer is the leading cause of cancer death in the United States, ${ }^{1,2}$ with a 5 -year survival rate (16\%) that is substantially lower

Conflicts of interest: autbors report none.

\section{CORRESPONDING AUTHOR}

Carrie N. Klabunde, $\mathrm{PhD}$

Applied Research Program Division of Cancer Control and Population Sciences

National Cancer Institute EPN 4005; 6130 Executive Blvd Bethesda, MD 20892-7344

KlabundC@mail.nih.gov the utility of screening patients for lung cancer, ${ }^{4-7}$ no randomized controlled trial has demonstrated that screening with chest radiograph or sputum cytology reduces mortality from lung cancer. ${ }^{8-11}$ In the United States, a large, randomized controlled trial comparing chest radiograph vs usual care has completed accrual, results assessing impact on lung cancer mortality are expected in late $2015 .{ }^{10}$ A second large, randomized controlled trial comparing low-dose spiral computed tomography (LDCT) vs chest radiograph in current and former heavy cigarette smokers, the National Lung 
Screening Trial (NLST), was halted in October 2010 after observation of a $20 \%$ reduction in lung cancer mortality in the LDCT group. ${ }^{11,12}$ To date, because of a lack of evidence from rigorous studies, major expert groups have not recommended screening asymptomatic individuals, even those with heavy or long-term smoking histories, for lung cancer. ${ }^{13-15}$ Whether expert groups will modify their lung cancer screening guidelines based on NLST results is at present unknown.

Past practice patterns raise concerns that NLST results may prompt overuse of lung cancer screening among average-risk patients. Despite the lack of strong evidence and guideline recommendations, prior studies have shown that many primary care physicians order chest radiographs to screen patients for lung cancer. ${ }^{16-19}$ In the US health care system (which is decentralized), LDCT and other radiologic screening tests are widely available and increasingly marketed, and patients can obtain them through self-referral. ${ }^{20,21}$ Because primary care physicians are many patients' initial point of contact with the health care system and coordinators of preventive care, they may have a role in ordering lung cancer screening tests or interpreting their results; however, national data on these physicians' knowledge, beliefs, and practices regarding lung cancer screening are sparse and out of date. Four national surveys conducted during the 1980s asked primary care physicians about their use of or recommendations for lung cancer screening with chest radiograph, results showed that up to $45 \%$ ordered or recommended it. ${ }^{16,17,22,23}$ No recent national survey of health care professionals has focused on lung cancer screening, nor has any assessed the use of other tests that have been considered for lung cancer early detection, such as sputum cytology and LDCT.

The National Cancer Institute (NCI) addressed this gap by sponsoring the National Survey of Primary Care Physicians' Recommendations \& Practices for Breast, Cervical, Colorectal, \& Lung Cancer Screening. ${ }^{24} \mathrm{We}$ previously used data from this survey to assess primary care physicians' knowledge and beliefs related to screening asymptomatic patients for lung cancer. ${ }^{25}$ In the present study, we use the data to examine US primary care physicians' self-reported lung cancer screening practices, including characteristics of those physicians who order lung cancer screening tests.

\section{METHODS}

\section{Survey Methods and Study Cohort}

We surveyed a nationally representative sample of primary care physicians between September 2006 and May 2007, using the American Medical Association's Physician Masterfile as the sampling frame. Eligible respondents were nonfederal, office-based family phy- sicians, general practitioners, general internists, and obstetricians-gynecologists aged 75 years or younger whose major activity was patient care. Physicians who were retired, deceased, or located outside the United States were excluded. We selected a systematic, stratified random sample of 2,576 primary care physicians using specialty type as the sampling strata and after sorting the sampling frame database by physician age, sex, and practice location. Physicians received up to 3 mailings of a questionnaire on colorectal and lung cancer screening, which had been cognitively tested in a convenience sample of 9 practicing primary care physicians before fielding. A $\$ 50$ prepaid honorarium was provided. Follow-up telephone calls were placed after the second and third mailings to encourage survey participation. Further details on survey methodology are published elsewhere. ${ }^{26}$ The survey was conducted under contract with Westat, a research organization in Rockville, Maryland, and approved by their institutional review board, as well as by the US Office of Management and Budget.

A total of 1,266 primary care physicians completed the survey. We restricted our study to the 3 primary care disciplines that see adult patients of both sexesfamily physicians, general practitioners, and general internists-which resulted in a sample of 962 physicians.

\section{Questionnaire Items and Measures}

Nine questionnaire items assessed primary care physicians' perceptions of the effectiveness of chest radiograph, sputum cytology, and LDCT as screening tests for reducing lung cancer mortality in asymptomatic patients aged 50 years and older (possible responses were "very effective," "somewhat effective," "not effective," "don't know"), with each item addressing the effectiveness of a combination of a given test with smoking status (never, former, current). Three items asked whether, during the past 12 months, the physicians had ordered a chest radiograph, sputum cytology, or LDCT to screen an asymptomatic patient for lung cancer ("yes," "no," "not sure.")

Physicians also were asked whether, to the best of their knowledge, each of 5 national organizations (US Preventive Services Task Force, ${ }^{13}$ American Cancer Society, ${ }^{27}$ American College of Radiology, ${ }^{28}$ American Thoracic Society, ${ }^{28} \mathrm{NCl}^{29}$ ) recommend lung cancer screening for asymptomatic, average-risk patients ("yes, recommends," "no, doesn't recommend," "not sure"). They then were asked whether, during the past 12 months, any of their patients had inquired about being screened for lung cancer, those responding "yes" gave estimates of how many patients had so inquired.

As previously described, ${ }^{25}$ we derived a measure of the intensity of the physicians' colorectal cancer 
screening recommendations from a set of vignettes asking them whether they would recommend screening patients of varying age and comorbidity for colorectal cancer. Our intent was to assess the influence of recommendations for another type of cancer screening on the ordering of lung cancer screening tests. Physicians who reported that they recommended colorectal cancer screening for patients with unresectable non-small cell lung cancer were categorized as high intensity in their colorectal cancer screening recommendations; all others were categorized as low or moderate intensity.

To create a measure of the physicians' propensity to recommend lung cancer screening, we used a set of 5 vignettes assessing whether physicians would recommend screening asymptomatic patients aged 50 years with various smoking histories for lung cancer: (1) never smoker, (2) never smoker with 20 years' exposure to secondhand smoke, (3) former smoker with a 20-pack-year history who quit 15 years ago, (4) former smoker with a 20-pack-year history who quit 1 year ago, and (5) current smoker with a 20-pack-year history. We grouped physicians according to the types of patients for whom they would recommend lung cancer screening: none; current and/or former smokers only; any smoking exposure, active or passive; and all, regardless of smoking exposure.

Other items asked about physicians' demographic and practice characteristics. The survey instrument is available online (http://healthservices.cancer.gov/ surveys/screening_rp/).

The American Medical Association's Physician Masterfile provided information on the primary care physicians' year of medical school graduation, medical school location (United States or international), sex, specialty, board certification, and geographic location. The zip code of the physician's primary practice location was mapped to Rural-Urban Commuting Area 2 (RUCA2) $\operatorname{codes}^{30}$ and subsequently categorized as urban, large rural city/town, or small/isolated small rural town.

\section{Data Analysis}

We used descriptive statistics to characterize the primary care physicians' beliefs about lung cancer screening guidelines and test effectiveness, and their lung cancer screening practices. We hypothesized that the physicians' lung cancer screening practices might vary by their personal and practice setting characteristics, practice style, beliefs about lung cancer screening guidelines and test effectiveness, and patient influence, based on prior studies that have shown these factors to influence physician behavior related to cancer screening and test ordering. ${ }^{25,31,32}$ We used $\chi^{2}$ statistics to assess the bivariate associations of these variables with
2 dependent measures: whether the physicians had ordered (1) a chest radiograph or (2) LDCT to screen an asymptomatic patient for lung cancer in the previous 12 months. Variables showing a statistically significant association at $P<.10$ were retained for inclusion in 2 multivariate logistic regression models. The first model examined characteristics of physicians who had ordered a chest radiograph; the second, characteristics of those who had ordered LDCT. All covariates were entered into the models simultaneously. We did not generate a separate model for sputum cytology because few physicians $(<5 \%)$ reported ordering this test.

Survey weights adjusting for undercoverage and survey nonresponse were applied in the analyses. The weighted data yield national estimates and their 95\% confidence intervals. We used SUDAAN version 9.0.1 (RTI International) in the analyses to account for the complex survey design.

\section{RESULTS}

\section{Survey Respondents}

A total of 962 of 1,363 eligible family physicians, general practitioners, and general internists completed the survey. The survey absolute response rate ${ }^{33}$ for these 3 specialties was therefore $70.6 \%$; the cooperation rate, which excluded the 100 physicians lacking valid contact information, was $76.8 \%$. Table 1 shows the respondents' demographic, practice setting, and practice style characteristics.

\section{Lung Cancer Screening Beliefs and Practices, and Patient Inquiries}

One-quarter of primary care physicians believed that 1 or more national expert groups recommend screening asymptomatic patients for lung cancer (Table 2). Physicians' beliefs about the effectiveness of screening tests in reducing lung cancer mortality in asymptomatic patients varied by test modality and patients' smoking status. For all 3 patient smoker statuses (never, former, current smokers), lower percentages of physicians expressed the belief that sputum cytology, compared with chest radiograph or LDCT, is effective in reducing lung cancer mortality. Higher percentages perceived LDCT as effective compared with chest radiograph. Physicians tended to rate the 3 tests (chest radiograph, sputum cytology, LDCT) as more effective in current than in never smokers.

More than one-half of physicians reported that, in the past 12 months, they had ordered chest radiograph to screen an asymptomatic patient for lung cancer, and nearly one-quarter had ordered LDCT (Table 2). In contrast, less than $5 \%$ reported ordering sputum cytology. Overall, 38\% had ordered no tests, while 57\% 
Table 1. Characteristics of Primary Care Physicians and Their Practice Settings ( $\mathrm{N}=962$ )

\begin{tabular}{|c|c|c|c|c|c|}
\hline Characteristic & $\begin{array}{l}\text { Unweighted } \\
\text { n }\end{array}$ & $\begin{array}{l}\text { Weighted } \\
\%\end{array}$ & Characteristic & $\begin{array}{l}\text { Unweighted } \\
\text { n }\end{array}$ & $\begin{array}{l}\text { Weighted } \\
\%\end{array}$ \\
\hline \multicolumn{3}{|l|}{ Physician characteristics } & \multicolumn{3}{|l|}{ Practice characteristics (continued) } \\
\hline \multirow{2}{*}{\multicolumn{3}{|c|}{$\begin{array}{l}\text { Years since graduation from medi- } \\
\text { cal school }\end{array}$}} & \multicolumn{3}{|l|}{ Type of health record system used } \\
\hline & & & Full EHR & 177 & 18.7 \\
\hline$<10$ & 136 & 14.0 & Partial EHR & 89 & 9.5 \\
\hline $10-19$ & 309 & 32.7 & Transitioning from paper to EHR & 144 & 15.2 \\
\hline $20-29$ & 288 & 30.5 & Paper charts & 545 & 55.9 \\
\hline$\geq 30$ & 229 & 22.8 & Missing & 7 & 0.8 \\
\hline \multicolumn{3}{|l|}{ Sex } & \multicolumn{3}{|l|}{ Patients uninsured, \% } \\
\hline Male & 680 & 70.4 & $0-5$ & 564 & 59.5 \\
\hline Female & 282 & 29.6 & $6-25$ & 291 & 29.6 \\
\hline \multicolumn{3}{|l|}{ Race/ethnicity } & $\geq 26$ & 68 & 6.8 \\
\hline White, non-Hispanic & 698 & 71.9 & Don't know/missing & 39 & 4.0 \\
\hline Asian & 149 & 15.3 & \multicolumn{3}{|l|}{ Physician practice style } \\
\hline Other $^{\mathrm{a}}$ & 115 & 12.8 & Has an affiliation with a medical & 316 & 33.8 \\
\hline \multicolumn{3}{|l|}{ Specialty } & school & & \\
\hline Family medicine & 481 & 50.7 & \multicolumn{3}{|l|}{ Patient volume during a typical week } \\
\hline General practice & 66 & 4.4 & $\leq 75$ & 316 & 32.7 \\
\hline General internal medicine & 415 & 45.0 & $76-100$ & 303 & 31.7 \\
\hline Board certified & 745 & 79.5 & $101-125$ & 202 & 21.3 \\
\hline International medical graduate & 236 & 24.4 & $\geq 126$ & 126 & 12.8 \\
\hline Practice characteristics & & & Missing & 15 & 1.5 \\
\hline \multicolumn{3}{|l|}{ Primary practice arrangement } & \multirow{2}{*}{\multicolumn{3}{|c|}{$\begin{array}{l}\text { Colorectal cancer screening } \\
\text { intensity }\end{array}$}} \\
\hline Full/part owner of practice & 521 & 53.8 & & & \\
\hline Employee or other/missing & 441 & 46.2 & Low/moderate & 605 & 62.8 \\
\hline \multicolumn{3}{|l|}{ Practice size (number of physicians) } & High & 322 & 33.9 \\
\hline 1 & 256 & 26.4 & Unknown & 35 & 3.4 \\
\hline $2-5$ & 400 & $\begin{array}{l}20.4 \\
41.7\end{array}$ & \multirow{2}{*}{\multicolumn{3}{|c|}{$\begin{array}{l}\text { Types of patients for whom the } \\
\text { physician would recommend lung } \\
\text { cancer screening }\end{array}$}} \\
\hline $6-15$ & 198 & 20.7 & & & \\
\hline$\geq 16$ & 102 & 10.6 & All, regardless of smoking & 167 & 17.2 \\
\hline Missing & 6 & 0.7 & exposure & & \\
\hline \multicolumn{3}{|l|}{ Geographic location } & $\begin{array}{l}\text { Any smoking exposure, passive } \\
\text { or active }\end{array}$ & 293 & 30.4 \\
\hline Urban $^{b}$ & 762 & 80.2 & \multirow{2}{*}{$\begin{array}{l}\text { Current and/or former smokers } \\
\text { only }\end{array}$} & \multirow[t]{2}{*}{184} & \multirow[t]{2}{*}{19.0} \\
\hline Large rural city/townc & 108 & 10.7 & & & \\
\hline Small/isolated small rural town ${ }^{d}$ & 92 & 9.1 & None & 308 & 32.3 \\
\hline \multicolumn{3}{|l|}{ Census region } & \multirow[t]{5}{*}{ Missing } & 10 & 1.0 \\
\hline Northeast & 184 & 19.9 & & & \\
\hline Midwest & 253 & 23.9 & & & \\
\hline West & 205 & 22.9 & & & \\
\hline South & 320 & 33.3 & & & \\
\hline \multicolumn{6}{|l|}{$\mathrm{EHR}=$ electronic health record. } \\
\hline \multicolumn{6}{|c|}{$\begin{array}{l}\text { a Includes Hispanic; black, non-Hispanic; American Indian/Alaska Native; Native Hawa } \\
{ }^{b} \text { Rural-Urban Commuting Area } 2 \text { (RUCA2) codes } 1.0,1.1,2.0,2.1,3.0,4.1,7.1 . \\
\text { ' } \text { RUCA2 codes 4.0, 4.2, 5.0, 5.2, } 6.0 . \\
{ }^{d} \text { RUCA2 codes } 7.0,7.2,7.3,7.4,8.0,8.2,8.3,9.0,9.1,10.0,10.2,10.4,10.5,10.6 \text {. }\end{array}$} \\
\hline
\end{tabular}

had ordered at least 1 of them. More than two-thirds of physicians reported that at least 1 patient in the past 12 months had asked them whether they could or should be screened for lung cancer.

In general, the percentages of physicians who had ordered lung cancer screening tests increased with their propensity to recommend screening asymptomatic patients for lung cancer (Figure 1). The propor- tions who had ordered such tests (chest radiograph and any test) were lowest among those who did not recommend screening and highest among those recommending screening for all patients, even patients without substantial smoking exposure. In contrast, a similar dose-response relationship was not observed for LDCT: although the percentages of physicians who had ordered LDCT were higher among those recommend- 


\begin{tabular}{|c|c|c|c|c|c|}
\hline Measure & $\begin{array}{l}\text { Unweighted } \\
\text { n }\end{array}$ & $\begin{array}{l}\text { Weighted \% } \\
(95 \% \mathrm{Cl})\end{array}$ & Measure & $\begin{array}{c}\text { Unweighted } \\
\text { n }\end{array}$ & $\begin{array}{l}\text { Weighted \% } \\
\text { (95\% Cl) }\end{array}$ \\
\hline Physician beliefs & & & Physician practices (continued) & & \\
\hline $\begin{array}{l}\text { Believes any expert group } \\
\text { recommends lung cancer } \\
\text { screening }\end{array}$ & 239 & $25.1(22.2-28.2)$ & $\begin{array}{l}\text { Patterns of lung cancer } \\
\text { screening tests ordered } \\
\text { in past } 12 \text { months }\end{array}$ & & \\
\hline \multirow{2}{*}{$\begin{array}{l}\text { Believes chest radiograph is } \\
\text { effective in reducing lung } \\
\text { cancer mortality for }\end{array}$} & & & Chest radiograph only & 329 & $34.0(30.9-37.2)$ \\
\hline & & & LDCT only & 34 & $3.6(2.5-5.3)$ \\
\hline Never smokers & 269 & $27.7(25.1-30.5)$ & $\begin{array}{c}\text { Chest radiograph and LDCT, } \\
\text { with or without sputum }\end{array}$ & 167 & $17.8(15.4-20.5)$ \\
\hline Former smokers & 510 & $52.4(49.0-55.8)$ & cytology & & \\
\hline Current smokers & 468 & $48.0(44.7-51.3)$ & Sputum cytology, with or & 21 & $2.0(1.3-3.0)$ \\
\hline \multirow{2}{*}{$\begin{array}{l}\text { Believes sputum cytology is } \\
\text { effective in reducing lung } \\
\text { cancer mortality for }\end{array}$} & & & $\begin{array}{l}\text { without chest radiograph } \\
\text { or LDCT }\end{array}$ & & \\
\hline & & & None & 360 & $37.6(34.9-40.4)$ \\
\hline Never smokers & 175 & $17.8(15.7-20.2)$ & Unknown & 51 & $5.0(3.7-6.7)$ \\
\hline Former smokers & 273 & $28.3(25.7-31.0)$ & Patient influence & & \\
\hline Current smokers & 319 & $33.3(30.5-36.3)$ & Number of patients who have & & \\
\hline \multirow{2}{*}{$\begin{array}{l}\text { Believes LDCT is effective in } \\
\text { reducing lung cancer mor- } \\
\text { tality for }\end{array}$} & & & $\begin{array}{l}\text { asked about lung cancer } \\
\text { screening in past } 12 \text { months }\end{array}$ & & \\
\hline & & & 0 & 293 & $30.3(27.7-33.0)$ \\
\hline Never smokers & 325 & $34.0(31.1-37.0)$ & $1-5$ & 253 & $26.2(23.2-29.4)$ \\
\hline Former smokers & 574 & $60.4(57.2-63.5)$ & $6-10$ & 174 & $18.4(15.8-21.4)$ \\
\hline Current smokers & 634 & $66.8(63.5-69.9)$ & $11-20$ & 119 & $12.5(10.5-14.8)$ \\
\hline Physician practices & & & $>20$ & 108 & $11.1(8.9-13.7)$ \\
\hline $\begin{array}{l}\text { Lung cancer screening tests } \\
\text { ordered in past } 12 \text { months }\end{array}$ & & & Unknown & 15 & $1.5(0.9-2.5)$ \\
\hline Chest radiograph & 530 & $55.3(52.0-58.4)$ & & & \\
\hline Sputum cytology & 41 & $4.5(3.3-6.2)$ & & & \\
\hline $\mathrm{LDCT}$ & 211 & $22.3(19.9-24.9)$ & & & \\
\hline
\end{tabular}

ing screening for asymptomatic patients compared with physicians who did not recommend screening, they did not vary by patients' smoking exposure.

\section{Characteristics of Physicians Who Ordered Lung Cancer Screening Tests}

Our 2 logistic regression models showed that several physician and practice characteristics were associated with the ordering of lung cancer screening tests for asymptomatic patients (Table 3 ).

The odds of ordering a chest radiograph compared with not ordering this test were significantly greater among physicians who graduated from medical school 20 to 29 years ago; believed that 1 or more expert groups recommend lung cancer screening or that chest radiograph is effective in reducing lung cancer mortality; saw 76 to 100 patients in a typical week; would recommend lung cancer screening for asymptomatic patients, regardless of smoking exposure; and had at least 1 patient ask them about lung cancer screening in the past 12 months.
The odds of ordering LDCT compared with not ordering this test were significantly greater among physicians who graduated from medical school 20 or more years ago; were general internists; were in practices with 6 to 15 physicians; believed that 1 or more expert groups recommend lung cancer screening or that LDCT is effective in reducing lung cancer mortality; would recommend lung cancer screening for asymptomatic patients, regardless of smoking exposure; or had patients ask them about lung cancer screening in the past 12 months.

\section{DISCUSSION}

To our knowledge, this is the first national study of primary care physicians' lung cancer screening practices to consider sputum cytology and LDCT_the new modality assessed in the recent NLST_-in addition to chest radiograph. Four prior national surveys have evaluated primary care physicians' use of or recommendations for chest radiograph ${ }^{15,16,21,22}$; however, 


\section{Figure 1. Percentage of primary care physicians who ordered lung cancer screening tests by types of patients for whom they would recommend lung cancer screening.}

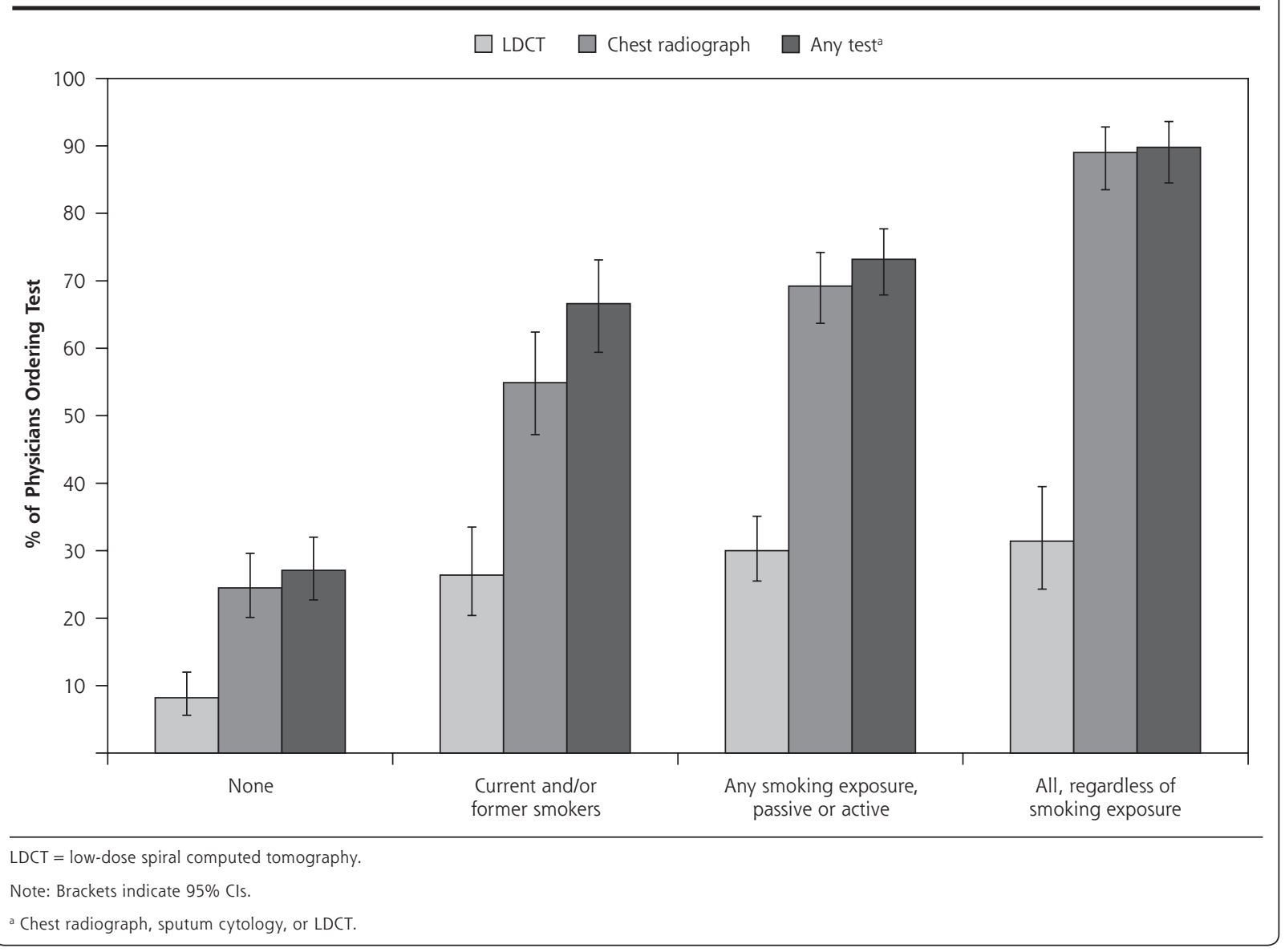

those surveys took place more than 2 decades ago and did not include all 3 primary modalities that have been considered for lung cancer early detection.

Our findings that a majority of primary care physicians reported ordering lung cancer screening tests for asymptomatic patients and that patients have recently asked them about lung cancer screening suggest that ordering of these tests is common among these physicians, as are patient-physician discussions about lung cancer screening, even though at the time of the survey, lung cancer screening was not recommended by major expert groups in the United States. Although direct comparison of our estimates with those of earlier studies ${ }^{16,17,22,23}$ is not possible because of differences in study designs, it appears that US primary care physicians have not decreased their practice of ordering chest radiographs to screen asymptomatic patients for lung cancer.

Primary care physicians' ordering of unproven lung cancer screening technologies has several implications. There is potential for psychological harm from false-positive or false-negative test results, and physical harm from invasive procedures performed to follow up false-positive screening tests. Results from the NLST's feasibility phase, the Lung Screening Study, indicated that the issue of false-positive results is nontrivial: the percentage of screened participants with a falsepositive examination was higher for LDCT than for chest radiograph, and LDCT showed a false-positive rate on an initial screen of $21 \%$ and on a second screen of $33 \% .{ }^{34}$ Imaging tests can also contribute to overdiagnosis of lung cancer and other conditions, ${ }^{35}$ and to radiation-induced cancers, especially with repeated LDCT examinations and the diagnostic imaging that often follows positive examinations. ${ }^{36,37}$ Finally, use of unproven lung cancer screening technologies ultimately drives up health care costs. ${ }^{37}$

To better understand reasons for primary care physicians' apparent overuse of lung cancer screening, we examined the potential influence of physician and practice setting characteristics, physician beliefs and practice style, and patient demand on physicians' lung cancer screening test ordering. We found in multivariate modeling that physicians who believe expert 
groups recommend lung cancer screening or that screening tests are effective in reducing lung cancer mortality, said they would recommend lung cancer screening for asymptomatic patients, or reported that their patients had asked them about being screened for lung cancer were significantly more likely to have ordered chest radiographs or LDCT as lung cancer screening tests in the past year. Physicians who graduated from medical school 20 years ago or more were significantly more likely to have ordered LDCT. Our findings that physician beliefs about screening and older physician age are associated with ordering lung cancer screening tests are consistent with previous studies of chest radiograph ordering. ${ }^{18,22,23}$ The finding that patient demand is associated with physicians' reports of lung cancer screening test ordering parallels earlier work showing that patient requests influence physicians' ordering of genetic tests for cancer susceptibility. ${ }^{32}$ Our assessment of physician characteristics associated with the ordering of lung cancer screening tests may aid efforts to target educational interventions to physicians most in need of updated information about lung cancer screening's evidence base and guidelines.

Strengths of this study include its large, nationally representative sample of practicing primary care physicians and high survey response rate. Our study also has some limitations. Physicians' self-reports of their lung cancer screening recommendations and practices were not validated with other data sources such as medical records or claims. To minimize respondent burden, the survey module on lung cancer screening was relatively brief, and we were not able to ask more detailed questions about specific characteristics of patients for whom physicians ordered lung cancer screening tests, such as type and extent of smoking exposure. We also did not ask whether the physician's practice had chest radiography available on site, which may influence chest radiograph ordering. Lastly, we did not ask to what extent physicians may be initiating discussions about lung cancer screening with their patients. All of these are key areas for future research on physicians' lung cancer screening recommendations and practices.

The disconnect between lung cancer screening evidence and practice that our study documents pro-
Table 3. Multivariate Models Assessing Factors Associated With Primary Care Physicians' Ordering of Lung Cancer Screening Tests

\begin{tabular}{|c|c|c|}
\hline Factor & $\begin{array}{l}\text { Ordered Chest } \\
\text { Radiograph } \\
\text { OR }(95 \% \mathrm{Cl})\end{array}$ & $\begin{array}{l}\text { Ordered LDCT } \\
\text { OR }(95 \% \mathrm{Cl})\end{array}$ \\
\hline \multicolumn{3}{|l|}{ Physician characteristics } \\
\hline \multicolumn{3}{|l|}{$\begin{array}{l}\text { Years since graduation from medical } \\
\text { school }\end{array}$} \\
\hline$<10$ & 1.0 & 1.0 \\
\hline $10-19$ & $1.2(0.7-2.3)$ & $1.7(0.9-3.3)$ \\
\hline $20-29$ & $2.2(1.2-4.1)^{\mathrm{a}}$ & $3.0(1.5-5.9)^{\mathrm{a}}$ \\
\hline$\geq 30$ & $1.5(0.8-3.0)$ & $2.5(1.3-5.0)$ \\
\hline \multicolumn{3}{|l|}{ Sex } \\
\hline Male & 1.0 & 1.0 \\
\hline Female & $1.2(0.8-1.8)$ & $0.8(0.5-1.4)$ \\
\hline \multicolumn{3}{|l|}{ Specialty } \\
\hline Family medicine/general practice & 1.0 & 1.0 \\
\hline General internal medicine & $1.2(0.8-1.7)$ & $1.6(1.1-2.4)^{\mathrm{a}}$ \\
\hline \multicolumn{3}{|l|}{ Board certified } \\
\hline Yes & 1.0 & 1.0 \\
\hline No & $0.8(0.5-1.3)$ & $0.9(0.6-1.5)$ \\
\hline \multicolumn{3}{|l|}{ Practice characteristics } \\
\hline \multicolumn{3}{|l|}{ Primary practice arrangement } \\
\hline Full/part owner of practice & $1.6(1.0-2.3)$ & $1.4(0.9-2.1)$ \\
\hline Employee or other/missing & 1.0 & 1.0 \\
\hline \multicolumn{3}{|l|}{ Practice size (number of physicians) } \\
\hline 1 & 1.0 & 1.0 \\
\hline $2-5$ & $0.1(0.7-1.7)$ & $1.5(0.9-2.5)$ \\
\hline $6-15$ & $1.4(0.8-2.4)$ & $1.9(1.1-3.3)^{\mathrm{a}}$ \\
\hline$\geq 16 /$ missing & $0.6(0.3-1.1)$ & $1.3(0.7-2.7)$ \\
\hline \multicolumn{3}{|l|}{ Census region } \\
\hline Northeast & 1.0 & 1.0 \\
\hline Midwest & $0.7(0.5-1.2)$ & $0.8(0.5-1.4)$ \\
\hline West & $1.0(0.6-1.6)$ & $0.8(0.5-1.5)$ \\
\hline South & $0.8(0.5-1.4)$ & $0.6(0.3-1.0)$ \\
\hline \multicolumn{3}{|l|}{ Type of health record system used } \\
\hline Full EHR & 1.0 & 1.0 \\
\hline Partial EHR & $0.7(0.4-1.2)$ & $0.9(0.4-2.0)$ \\
\hline Transitioning from paper to EHR & $1.2(0.7-2.1)$ & $0.6(0.3-1.1)$ \\
\hline Paper charts/missing & $1.1(0.7-1.7)$ & $0.8(0.4-1.4)$ \\
\hline \multicolumn{3}{|l|}{ Patients who are uninsured, $\%$} \\
\hline $0-5$ & 1.0 & 1.0 \\
\hline $6-25$ & $0.9(0.6-1.4)$ & $1.0(0.6-1.5)$ \\
\hline$\geq 26 /$ don't know/missing & $0.5(0.3-1.0)$ & $0.6(0.3-1.1)$ \\
\hline \multicolumn{3}{|l|}{ Physician beliefs } \\
\hline \multicolumn{3}{|c|}{$\begin{array}{l}\text { Believes any expert group recommends } \\
\text { lung cancer screening }\end{array}$} \\
\hline No & 1.0 & 1.0 \\
\hline \multirow[t]{2}{*}{ Yes } & $1.7(1.1-2.9)^{\mathrm{a}}$ & $1.8(1.2-2.8)^{\mathrm{a}}$ \\
\hline & & Table 3 continues \\
\hline
\end{tabular}

vides important context for considering the potential consequences of the recent, highly publicized NLST findings. ${ }^{38}$ Those findings are specific to individuals aged 50 to 75 years who were current or former smokers with at least a 30 -pack-year history of smoking. 


\section{Table 3. Multivariate Models Assessing Factors Associated With Primary Care Physicians' Ordering of Lung Cancer Screening Tests (continued)}

\begin{tabular}{|c|c|c|}
\hline Factor & $\begin{array}{l}\text { Ordered Chest } \\
\text { Radiograph } \\
\text { OR }(95 \% \mathrm{Cl})\end{array}$ & $\begin{array}{l}\text { Ordered LDCT } \\
\text { OR }(95 \% \mathrm{Cl})\end{array}$ \\
\hline \multicolumn{3}{|l|}{ Physician beliefs (continued) } \\
\hline \multicolumn{3}{|l|}{ Believes LDCT is effective for } \\
\hline $\begin{array}{l}\text { Never, former, and current smokers } \\
\text { (all 3) }\end{array}$ & - & $8.2(3.3-20.6)^{\mathrm{a}}$ \\
\hline Never, former, or current smokers & - & $6.0(2.3-15.8)^{\mathrm{a}}$ \\
\hline No patients & - & 1.0 \\
\hline \multicolumn{3}{|l|}{ Physician practice style } \\
\hline \multicolumn{3}{|l|}{ Patient volume during a typical week } \\
\hline$\leq 75$ & 1.0 & 1.0 \\
\hline $76-100$ & $1.7(1.1-2.7)^{\mathrm{a}}$ & $1.1(0.7-1.9)$ \\
\hline $101-125$ & $1.6(1.0-2.6)$ & $1.0(0.6-1.8)$ \\
\hline$\geq 126 /$ missing & $1.1(0.7-1.8)$ & $1.5(0.8-3.0)$ \\
\hline \multicolumn{3}{|l|}{$\begin{array}{l}\text { Intensity of colorectal cancer screening } \\
\text { recommendations }\end{array}$} \\
\hline Low/moderate & 1.0 & 1.0 \\
\hline High & $1.0(0.6-1.4)$ & $0.7(0.5-1.1)$ \\
\hline Unknown & $1.3(0.5-3.1)$ & $0.9(0.4-1.8)$ \\
\hline \multicolumn{3}{|l|}{$\begin{array}{l}\text { Types of patients for whom physician } \\
\text { recommends lung cancer screening }\end{array}$} \\
\hline All, regardless of smoking exposure & $14.6(7.0-30.4)^{\mathrm{a}}$ & $2.1(1.1-4.0)^{\mathrm{a}}$ \\
\hline $\begin{array}{l}\text { Any smoking exposure, active or } \\
\text { passive }\end{array}$ & $4.6(3.1-6.8)^{\mathrm{a}}$ & $2.9(1.7-5.0)^{\mathrm{a}}$ \\
\hline Current and/or former smokers only & $2.4(1.5-4.0)^{\mathrm{a}}$ & $2.4(1.4-4.2)^{\mathrm{a}}$ \\
\hline None & 1.0 & 1.0 \\
\hline \multicolumn{3}{|l|}{ Patient influence } \\
\hline \multicolumn{3}{|l|}{$\begin{array}{l}\text { Number of patients who have asked } \\
\text { about lung cancer screening in past } \\
12 \text { months }\end{array}$} \\
\hline 0 & 1.0 & 1.0 \\
\hline $1-5$ & $2.7(1.8-3.9)^{\mathrm{a}}$ & $1.8(1.1-3.0)^{\mathrm{a}}$ \\
\hline $6-10$ & $2.9(1.9-4.6)^{\mathrm{a}}$ & $2.0(1.1-3.5)^{\mathrm{a}}$ \\
\hline$>10$ & $5.3(3.2-8.8)^{\mathrm{a}}$ & $3.2(1.9-5.6)^{\mathrm{a}}$ \\
\hline Unknown & $1.3(0.2-8.4)$ & $1.7(0.4-7.4)$ \\
\hline
\end{tabular}
Note: Race/ethnicity, geographic location, and medical school affiliation were not included in the models because these measures were not statistically significant in bivariate analyses at $P<.10$.

a Indicate a statistically significant odds ratio.
EHR = electronic health record; $L D C T$ = low-dose spiral computed tomography; OR = odds ratio.

Finally, 3 additional factors heighten the need for educating primary care physicians and patients about lung cancer screening's evidence base, guidelines, potential harms, and costs. First, anecdotal evidence suggests that announcement of NLST results may have prompted some medical professionals to more widely promote lung cancer screening and their LDCT facilitie $^{37}$; second, the US general public has an overly positive view of cancer screening and limited understanding of its potential harms ${ }^{39}$; and third, use of computed tomography scans in general is rising rapidly in the United States. ${ }^{40}$ These factors along with our study's results and the evolving evidence base underscore the importance of continued monitoring of primary care physicians' knowledge, beliefs, and practices related to lung cancer screening.

To read or post commentaries in response to this article, see it online at http://www.annfammed.org/ content/10/2/102.

Key words: lung cancer; screening; primary care; physicians; physician's practice patterns

Submitted April 7, 2011; submitted, revised, August 2, 2011; accepted August 23, 2011.

Funding support: Funding support for the study was provided by the National Cancer Institute (contract N02-PG-51308), the Agency for Healthcare Research and Quality (interagency agreements Y3-PC-5019-01 and Y3-PC-5019-02), and the Centers for Disease Control and Prevention (interagency agreement Y3-PC-6017-01). In addition, Dr Vernon is supported by $\mathrm{NCl}$ grant R01 CA112223, and Dr Silvestri by an NCl investigator grant in patient-oriented research (K24 CA120494-2) and a Department of Defense grant in computer-aided cancer management (W81XWH-05-1-0378).

Disclaimer: The findings and conclusions in this report are those of the authors and do not necessarily represent the official position of the National Cancer Institute or

Any change in screening recommendations that might occur as a result of the NLST would apply only to this select, high-risk population and 1 specific technology (ie, LDCT). Our results showing gaps in primary care physicians' knowledge of lung cancer screening and use of unproven screening modalities suggest that in the United States-where most cancer screening occurs opportunistically rather than through organized programs-a substantial proportion of the adult population could be inappropriately screened unless there are concerted efforts to inform primary care physicians of appropriate interpretation of NLST findings and how best to apply them in practice. the Centers for Disease Control and Prevention.

\section{References}

1. Jemal A, Siegel R, Xu J, Ward E. Cancer statistics, 2010. CA Cancer J Clin. 2010;60(5):277-300.

2. US Cancer Statistics Working Group. United States Cancer Statistics: 1999-2007 Incidence and Mortality Web-based Report. Atlanta, GA: US Department of Health and Human Services, Centers for Disease Control and Prevention, and National Cancer Institute, 2010. http://apps.nccd.cdc.gov/uscs/. Accessed Feb 8, 2012.

3. Miser WF. Cancer screening in the primary care setting: the role of the primary care physician in screening for breast, cervical, colorectal, lung, ovarian, and prostate cancers. Prim Care. 2007;34(1): 137-167. 
4. Petty TL. Screening strategies for early detection of lung cancer: the time is now. JAMA. 2000;284(15):1977-1980.

5. Frame PS. Routine screening for lung cancer? Maybe someday, but not yet. JAMA. 2000;284(15):1980-1983.

6. Carlow DR. New approaches to lung cancer. Changing role for family physicians. Can Fam Physician. 2001;47:469-471, 476-478.

7. Lee $\mathrm{Cl}$, Forman HP. CT screening for lung cancer: implications on social responsibility. AJR Am J Roentgenol. 2007;188(2):297-298.

8. Berlin NI. Overview of the $\mathrm{NCl}$ Cooperative Early Lung Cancer Detection Program. Cancer. 2000;89(11 Suppl):2349-2351.

9. Marcus PM, Bergstralh EJ, Fagerstrom RM, et al. Lung cancer mortality in the Mayo Lung Project: impact of extended follow-up. J Natl Cancer Inst. 2000;92(16):1308-1316.

10. National Cancer Institute. About Prostate, Lung, Colorectal \& Ovarian Cancer Screening Trial. http://dcp.cancer.gov/plco. Accessed Feb 8, 2012.

11. National Cancer Institute. National Lung Screening Trial. Updated June 29, 2011. http://www.cancer.gov/NLST. Accessed Feb 8, 2012.

12. National Cancer Institute. National Lung Screening Trial: Questions and Answers. Updated June 29, 2011. http://www.cancer.gov/ newscenter/qa/2002/nlstqaQA. Accessed Feb 8, 2012.

13. US Preventive Services Task Force. Lung cancer screening: recommendation statement. Ann Intern Med. 2004;140(9):738-739.

14. Smith RA, Cokkinides V, Brawley OW. Cancer screening in the United States, 2009: a review of current American Cancer Society guidelines and issues in cancer screening. (A Cancer J Clin. 2009;59(1):27-41.

15. Bach PB, Silvestri GA, Hanger M, Jett JR; American College of Chest Physicians. Screening for lung cancer: ACCP evidence-based clinical practice guidelines (2nd edition). Chest. 2007;132(3 Suppl):69S-77S.

16. American Cancer Society. Survey of physicians' attitudes and practices in early cancer detection. CA Cancer J Clin. 1985;35(4):197-213.

17. American Cancer Society. 1989 survey of physicians' attitudes and practices in early cancer detection. CA Cancer J Clin. 1990;40(2):77-101.

18. Sladden MJ, Ward JE. Do Australian family physicians screen smokers for lung cancer? Chest. 1999;115(3):725-728.

19. Mauri D, Kamposioras K, Proiskos A, et al. Old habits die hard: chest radiography for screening purposes in primary care. Am J Manag Care. 2006;12(11):650-656.

20. Lee TH, Brennan TA. Direct-to-consumer marketing of high-technology screening tests. N Engl J Med. 2002;346(7):529-531.

21. Fenton JJ, Deyo RA. Patient self-referral for radiologic screening tests: clinical and ethical concerns. J Am Board Fam Pract. 2003;16(6):494-501.

22. Bergner M, Allison CJ, Diehr P, Ford LG, Feigl P. Early detection and control of cancer in clinical practice. Arch Intern Med. 1990;150(2):431-436.

23. Schwartz JS, Lewis CE, Clancy C, Kinosian MS, Radany MH, Koplan JP. Internists' practices in health promotion and disease prevention. A survey. Ann Intern Med. 1991;114(1):46-53.
24. National Cancer Institute. National Survey of Primary Care Physicians' Recommendations \& Practices for Breast, Cervical, Lung, \& Colorectal Cancer Screening. Last modified October 8, 2008. http:// healthservices.cancer.gov/surveys/screening_rp/. Accessed Feb 8, 2012

25. Klabunde CN, Marcus PM, Silvestri GA, et al. U.S. primary care physicians' lung cancer screening beliefs and recommendations. Am J Prev Med. 2010;39(5):411-420.

26. Klabunde CN, Lanier D, Nadel MR, McLeod C, Yuan G, Vernon SW. Colorectal cancer screening by primary care physicians: recommendations and practices, 2006-2007. Am J Prev Med. 2009;37(1):8-16.

27. Smith RA, Cokkinides V, Eyre HJ. American Cancer Society guidelines for the early detection of cancer, 2006. CA Cancer J Clin. 2006;56(1):11-25, quiz 49-50.

28. Agency for Healthcare Research and Quality. National Guideline Clearinghouse. http://www.guideline.gov. Accessed Feb 8, 2012.

29. National Cancer Institute. Lung cancer screening (PDQ): health professional version. Last modified July 22, 2011. http://www.cancer .gov/cancertopics/pdq/screening/lung/healthprofessional. Accessed Feb 8, 2012.

30. University of Washington Rural Health Research Center. RuralUrban Commuting Area Codes (RUCAs). http://depts.washington .edu/uwruca. Accessed Feb 8, 2012.

31. Zapka JG, Lemon SC. Interventions for patients, providers, and health care organizations. Cancer. 2004;101(5 Suppl):1165-1187.

32. Wideroff L, Freedman AN, Olson L, et al. Physician use of genetic testing for cancer susceptibility: results of a national survey. Cancer Epidemiol Biomarkers Prev. 2003;12(4):295-303.

33. American Association for Public Opinion Research. Standard Definitions: Final Dispositions of Case Codes and Outcome Rates for Surveys-Revised 2009. http://www.aapor.org/Content/Navigation Menu/ResourcesforResearchers/StandardDefinitions/StandardDefini tions2009new.pdf. Accessed Feb 8, 2012.

34. Croswell JM, Baker SG, Marcus PM, Clapp JD, Kramer BS. Cumulative incidence of false-positive test results in lung cancer screening: a randomized trial. Ann Intern Med. 2010;152(8):505-512, W176-W180.

35. Edey AJ, Hansell DM. CT lung cancer screening in the UK. Br J Radiol. 2009;82(979):529-531.

36. Brenner DJ, Hall EJ. Computed tomography-an increasing source of radiation exposure. N Engl J Med. 2007;357(22):2277-2284.

37. Peres J. Lung cancer screening: ready for prime time? J Natl Cancer Inst. 2011;103(2):89-91.

38. The National Lung Screening Trial Research Team. Reduced lungcancer mortality with low-dose computed tomographic screening. N Engl J Med. 2011;365(5):395-409.

39. Schwartz LM, Woloshin S, Fowler FJ Jr, Welch HG. Enthusiasm for cancer screening in the United States. JAMA. 2004;291(1):71-78.

40. Smith-Bindman R. Is computed tomography safe? N Engl J Med. 2010;363(1):1-4 